\title{
Coronavirus Disease-2019 (COVID-19) Crisis: Will It Save Or Pollute the Environment?
}

Abdelaziz Ghanemi*

Laval University, Québec, Québec province, G1V 0A6, Canada

*Corresponding author: Abdelaziz Ghanemi, Laval University, 2325, rue de l'Université, Québec (Québec) G1V 0A6 Canada,

Email: abdelaziz.ghanemi.1@ulaval.ca

Graphical abstract

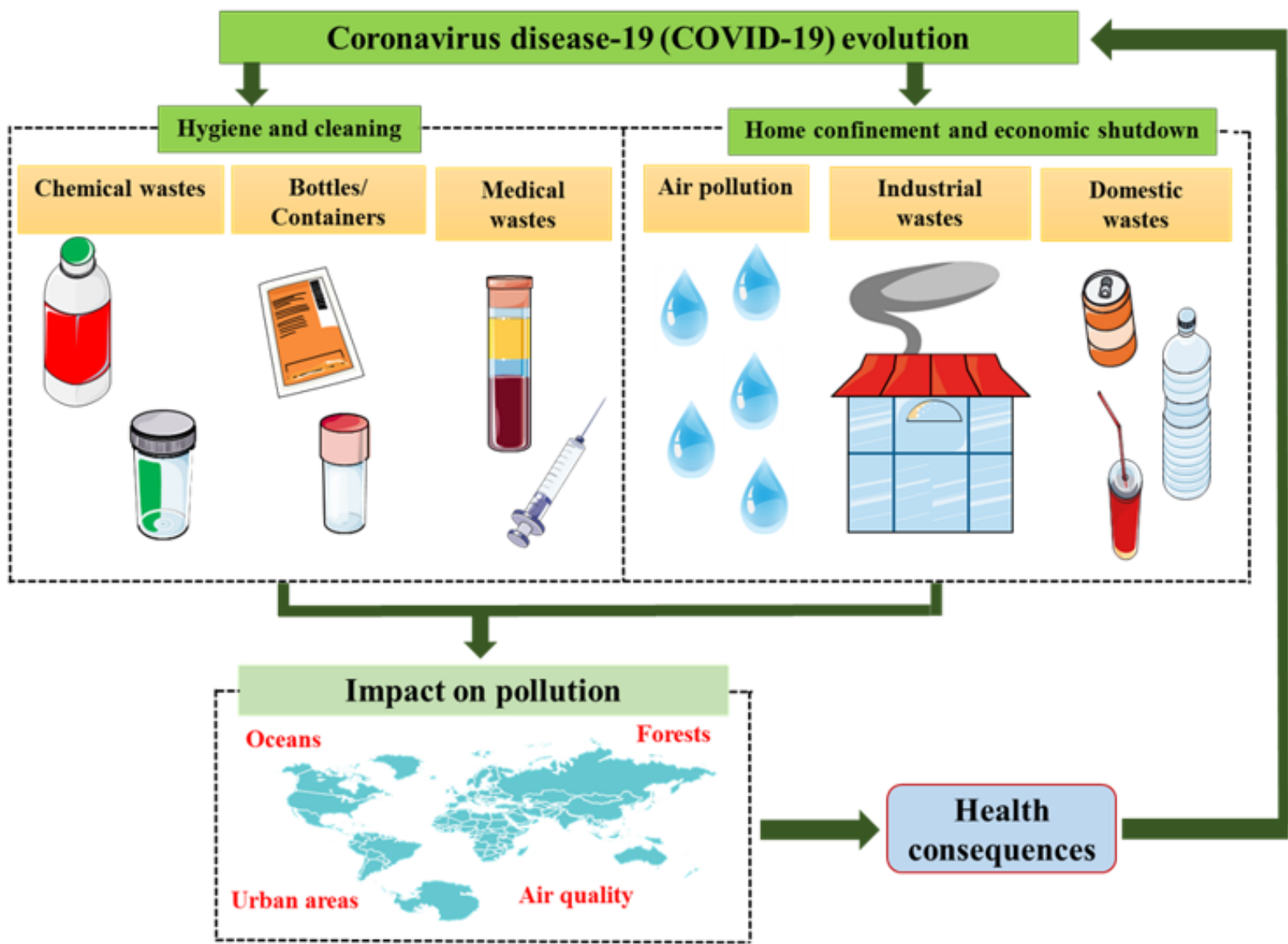

Keywords: Coronavirus disease-2019 (COVID-19); Pollution 


\section{Short Communication}

With the ongoing pandemic of coronavirus disease-2019 (COVID-19) and its trend [1] have led to changes at many levels including chemical industry, tourism, travel, pharmaceutic, etc. All that is not without consequences on the oceans and the environment in general (including forests and rivers). Herein, we discuss to which extend the COVID-19 consequences on different factors related to the ecological system [2] and life homeostasis in oceans and on our globe in general. One on the principles practices recommended by health authorities is the hygiene at all levels, starting form hand washing and the use of alcoholic gels to surfaces disinfection and public places cleaning. Therefore, there have been a significant increase in the use of all the related products including medical wastes. All these generates a serious amount of chemical wastes in addition to all what is used for packing those products such as plastic bottles [3]. In addition, home confinement increases food consumption and other goods. Furthermore, the psychological impact of the confinement could also induce more alcohol and cigarette usage which also increases domestic wastes as well. This will seriously increase the pollution rates especially that most countries do not have efficient recycling (both for chemicals and materials) which is worsen by the slowdown of divers activities including those of the recycling stations.

Ironically, increase pollution might worsen medical COVID-19 impact on the polluted region [4]. Furthermore, the pollution leads to develop or worsen numerous diseases $[5,6]$ such as which would increase the vulnerability to the individuals to a number of diseases such as COVID-19 itself. On the other hand, other signs of pollution (such as air pollution) have been reported to significantly decrease following the economic lock down and the home confinements that lead to an industrial waste and gas (that results from industry and transport). This lead to a "purification" of the air via reducing air pollution [7]. Indeed, suspended air traffic, road traffic, individuals working from home has reduced the emissions. The final environmental impact would not only depend on how these two directions (those reducing pollution and those increasing it) go but also for how long the situation will remain. In fact, with the restart of the economy is some countries that have overcome the critical phase of COVID-19, it is expected that the industrial wastes and emissions will quickly increase since the activities will resume with an increases power in order to make up the period of the industrial shutdown. Therefore, could come back in a more severe form. However, the effect of COVID-19 on the environment including the fats air quality improvement $[8,9]$ leaves us with a hope that there is still time to save the planet and faster that we could imagine if the right decisions are taken. This is of a particular importance especially after we have seen what we are able to do and we can scape in our daily lives among what we thought to be required.

\section{Potential Conflicts of Interest}

None (The author declares that there is no conflict of interests)

\section{Acknowledgement}

Abdelaziz Ghanemi is a recipient of a Merit scholarship program for foreign students from the Ministry of Education and Higher Education of Quebec, Canada, The Fonds de recherche du Québec - Nature et technologies (FRQNT) is responsible for managing the program (Bourses d'excellence pour étudiants étrangers du Ministère de l'Éducation et de l'Enseignement supérieur du Québec, Le Fonds de recherche du Québec - Nature et technologies (FRQNT) est responsable de la gestion du programme). The graphical abstract was created using images from: http://smart.servier. com. Servier Medical Art by Servier is licensed under a Creative Commons Attribution 3.0 Unported License and Scidraw.io.

\section{References}

1. Kannan S (2020) COVID-19 (Novel Coronavirus 2019) - recent trends. Eur Rev Med Pharmacol Sci 24(4): 2006-2011.

2. Dutheil F, JS Baker, VNavel (2020)COVID-19 as a factor influencing air pollution? Environ Pollut 263(Pt A): pp.114466.

3. Rhodes CJ (2018) Plastic pollution and potential solutions. Sci Prog 101(3): 207-260.

4. Frontera A (2020) Severe air pollution links to higher mortality in COVID-19 patients: The "double-hit" hypothesis. J Infect 81(2): 255-259.

5. Kim KH, E Kabir, S Kabir (2015) A review on the human health impact of airborne particulate matter. Environ Int 74: 136-143.

6. Nigra AE (2016) Environmental Metals and Cardiovascular Disease in Adults: A Systematic Review Beyond Lead and Cadmium. Curr Environ Health Rep 3(4): 416-433.

7. Muhammad S, X Long, M Salman (2020) COVID-19 pandemic and environmental pollution: A blessing in disguise? Sci Total Environ 728: pp. 138820.

8. Mahato S, S Pal,KG Ghosh (2020) Effect of lockdown amid COVID-19 pandemic on air quality of the megacity Delhi, India. Sci Total Environ 730: pp.139086.

9. Li L (2020) Air quality changes during the COVID-19 lockdown over the Yangtze River Delta Region: An insight into the impact of human activity pattern changes on air pollution variation. Sci Total Environ, 732: pp.139282. 
(C) (P) This work is licensed under Creative

To Submit Your Article Click Here: Submit Article

DOI: $10.32474 /$ RRHOAJ.2020.05.000222

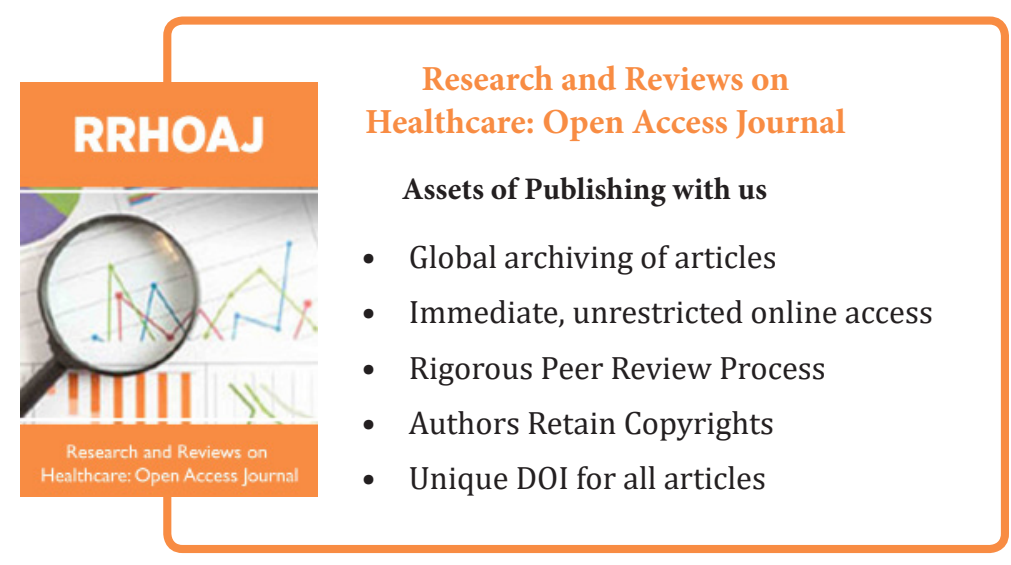

